\title{
A Pandemic Circumscribing another Pandemic: The Covid 19 World of Disabled Women
}

\author{
Gokul S \\ Research Scholar, Department of English Literature, the English and Foreign Languages \\ University, Hyderabad, gokulloyola13@gmail.com, ORCID id: oooo-ooo1-8969-1570
}

\begin{abstract}
Accessibility and inclusion have always been a major impediment in the lives of the disabled. As a result, their lives have always been ontologically nebulous from the gaze of the outside world. Covid-19 has brought new norms of normalcy and extrapolating social behaviour such as social distancing. Such a regimented form of behaviour has ossified even further the problems of inclusion and accessibility. The upsurge of the pandemic has further complicated the forms of social behaviour and thereby adding more to the disability of an already disabled. This paper aims to analyze the problems of this new behavioural norm by the espousal of a centrifugal outlook and multilateral imagination keeping the disabled as the focal point of discussion. It also explains vis-a-vis Foucault's idea of Bio politics, the ways new norm installs amongst people a different kind of solidarity based upon a common idea of vulnerability.
\end{abstract}

Keywords: Pandemic, Disabled, Women, Accessibility, Inclusion, Bio-politics.

Accessibility and inclusion have always been a biggest ordeal in the life of the disabled. The medical model of disability has only focused and is concerned about the individual as an impaired body which has to be treated and cured for his impairment. Whereas the social model of disability argues that society fails to accommodate impaired bodies. The disability rights activist has constantly maintained the clarion call that 'Nothing about us, without us'. As a result of the impact of the social model, the countries are trying to accommodate persons with disabilities (PWD) by addressing the major concerns of accessibility and inclusion. Even though a lot of issues and concerns was not addressed at the beginning like social security, healthcare and insurance schemes were addressed in future amendments, the disabled community is happy about the representation and recognition which they get through the acts like American Disabilities Act (1990), PWD Act (equal opportunities, protection of rights and full participation) and RPWD in India (1995 and 2016). When it comes to implementation of these acts in India, PWD's are still fighting for their rights.

In India if a disabled is born in a family, people often make it appear as a taboo that it is due to the past sins committed by the family or the individual that $\mathrm{s} /$ he is born in such a way. The family searches for the treatment of disability through various ways rather than accepting the reality. This makes their accommodation even more difficult though the reasonable accommodation of the disabled which is still fought through legal aid and activism. At the same time, issues of women are countless in today's digital era. There have been lot of reformers like Raja Ram Mohan Roy and Jyotirao Phule and organisations like Azad foundation and Self Employed Women's Association which continue to address and advocate the rights and equality

(C) AesthetixMS 2020. This Open Access article is published under a Creative Commons Attribution Non-Commercial 4.0 International License (http://creativecommons.org/licenses/by-nc/4.0/), which permits non-commercial re-use, distribution, and reproduction in any medium, provided the original work is properly cited. For citation use the DOI. For commercial re-use, please contact editor@rupkatha.com. 
of women for decades. Disabled women are even excluded from consideration in these movements. It took them decades to voice out their rights which are hitherto relegated to the margins. Their voice is being heard but in a limited manner. For instance, there exist narratives written by Indian disabled men by Ved Mehta and Firdus kanga during 1980's, on the other hand the life narratives of Indian disabled women by Naseema Huzruk and Preeti Monga are found post 200o's onwards. So it took almost a century, for disabled women to speak for themselves. The arrival of Covid has made them disappear from the globe altogether. The new power configurations and incorporation of hierarchies through system regulated mechanisms encourages elimination of those who are useless and underprivileged.

Covid'19 is not new to the world as the globe has witnessed pandemics earlier as well. One thing that is unique to Covid is the kind of self regulated, vigilant and regimented behaviour it promotes. It not only encourages ones responsibility towards oneself but also provides people with a moral imperative to be equally responsible for society. It promotes a selective kind of solidarity based on a common apparatus of vulnerability. Shelley Tremain argues that this idea of promoting vulnerability is a population management technique. She argues that people are not always already vulnerable; they are made vulnerable through certain segregation techniques. Tremain (2020) states,

"No one is a criminal, but many people are illegalized in this way. No one is an illegal immigrant, but many people are illegalized in this way. No one has a race or a disability, but people are racialized and disabled. No one is a vulnerable (to use Eva Kittay's term), but many people (including seniors, disabled people, and prisoners) are vulnerableized".

Such a project has different impacts on abled and disabled bodies. Where women are already tackling with their subsumed status in the society, this added vulnerability brings more misery to their lives. Effeminized representation of disabled people often brings a similar set of problems for them including that of accessibility and inclusion.

Again, accessibility and inclusion has lot of dimensions within itself. These both can be spoken on the grounds of digital and physical spaces, for instance, the limited accessibility of information and the ways disabled women are more vulnerable than disabled men. In India, when lockdown is imposed, within few hours people are seen rushing to the markets to store their essentials, but this news to reach the unheard ears (hearing impaired) itself took time. They had no time to prepare for the sudden lockdown. This communication gap brought fear and anxiety rather than providing information to the community. People with visual impairment failed to understand these visual mechanisms which illustrated right ways of washing hands and without verbal instructions. People with loco motor disability had to face a similar crisis as they too are interdependent on caregivers for their wheels to move. Tremain(2020), once again reminding of Foucault talks about how disability is an extension of the same vulnerability. It serves as a readymade "apparatus of power that differentially produces subjects, materially, socially and politically". It produces an invisible minority who are already on the verge of disappearance from the public sphere. In Foucauldian terminology, the process of segregating between the sane/insane, mad/normal, vulnerable/ non-vulnerable has a network of power operating beneath it. The elimination and inclusion is directly proportional to the individual's contribution to the social apparatus and social anatomy. Similarly, those who must die and those who are to live is a conscious decision which is presented as an understandable consequence of one's own vulnerability. Back in the middle-ages, people who are classified as mad are transferred to the margins of the city as madness is considered to be threatening for the social normative. Covid has 
made their task easier as people themselves are willingly isolating themselves without the assistance of external repressive social apparatus.

The more visible exercises of power are seen in private sphere. Though people are advised to stay indoors, it is ironic that home is not always a favourable place in the life of disabled. Their lives are already miserable right from the time they are born, be it in rural poverty or urban elite households. It has its own paradigm of complexities in accessibility, exposure and inclusion in everyday life due to the economical differences. When every one is made to stay indoors, the excluded start facing its worst repercussions in every household of this country and this remains unnoticed. The issues pertaining to gender based violence on disabled are witnessed quite often in the times of lockdown. It is true that such issues are common to all women, yet it is not same for abled women and disabled women. The 1993 UN General assembly for elimination of violence against women defines Gender based violence as

"any act of gender based violence that results in, or is likely to result in physical, sexual or psychological harm or suffering to women, including threats of such acts coercion or arbitrary deprivation of liberty whether occurring in public or private life".(WHO,1).

Prior to the arrival of Covid 19 the situation is not favorable, but in new normal it has become almost intolerable. Gender based violence can be further classified as domestic and sexual violence. During lockdown a similar instance of sexual violence came to light, where a family decides to get rid of their disabled daughter. Times of India, Jaipur (May 24, 2020) has reported that a ten year old intellectually impaired girl is found missing from May $17^{\text {th }}$ and on May $21^{\text {st }}$ she is found dead. The investigation reveals that her own brother is assigned the job to kill her. He along with his three friends raped and murdered her. This is evident of the fact that even home is not a safer place for a disabled. Such incidents use to happen even before lockdown but it is crucial address the ways lockdown adds complexity to their lives.

The National Platform for the Rights of the Disabled (NPRD) condemns the rape and murder of a 12-year-old hearing and speech impaired girl in Gujarat. The minor girl is abducted on October 16, and is found with her throat slit in a field at a village in Banaskantha district on October 17 morning. Such cases add to the misery of women with disabilities. Similarly, on August 24, 2020 a minor deaf girl was raped and murdered in Paingaltu village, District Palwal in Haryana. In early August another speech-impaired girl was raped in Dausa district of Rajasthan. There are also cases which never come to surface and are brushed under the carpet. In other cases, victims are murdered after sexual assault just to destroy evidence. A more recent example is the Hathras and Balrampur cases in Uttar Pradesh, where the victims are not disabled. Such incidents are not new to the world but the increasing brutality shocks each one of us. The worst part is the insensitivity of the police and the administration to the issues of the disabled victims/survivors. Despite cases of sexual assaults being reported on a regular basis the National Crime Records Bureau does not maintain disaggregated data about such violence. Rising flames and sight savers India (2020) has come up with a report titled 'Neglected and Forgotten; women with disabilities during the covid crisis in India'. This report brought out the issues of Indian disabled women like access, social protection, health, education in global and local context. This report also suggest immediate recommendations for inclusion of WWD's during the time of disaster based on RPWD Act and UNCRPD guidelines.

Women with intellectual and speech impairment are more vulnerable amongst disabled women as they fail to express what actually happens with them owing to their impairment. When one's own family members become predators there remains no safer niche for the disabled 
women. Their lives become even a tougher and gruesome challenge which they have to bear alone. The Deccan Herald on $31^{\text {st }}$ March 2020 claimed in a report that there is a rise in domestic violence with the onset of lockdown. Captivity frustrates them and abuses make it worse. In a patriarchal society, the unemployed women are dependent on their husbands. In this lockdown, sudden salary cuts and reduction of man power brought frustration in men and this usually resulted in violence. For disabled women, there is no accurate account of how far their episodes of domestic violence are recorded or how many of them are able to voice out their concerns. In this manner, disabled are completely absent from the picture. The commission has started receiving complaints of atrocities committed against women. Even worse is the case in rural India which doesn't have high speed internet and awareness about such commissions.

Where could you find a disabled woman in this picture? They have become voiceless. The hierarchical construction of society is mostly gender oriented. In this too, it is women who have a fixed role such as that of a daughter, mother and wife. It has become harder for disabled women who are not given proper care and rehabilitation to perform these roles at home during lockdown. They are constantly made to feel that their existence is insignificant and the tasks they accomplish hold little or no significance. Even after attending to most of the chores at home, they have to remain silent to avoid fights at home when they are targeted for no fault of their own. Because of unavailability of work during lockdown, male members are already frustrated. In general, the household work is considered pointless labour as it is very repetitive and unproductive in terms of financial output. When disabled women are reduced to a committal of only household chores their work is adjudged in even more disapproving tones. They are reminded of their mutated existence at all times and the worst part is that they cannot even express their feelings. Dr. Sadhana Natu (2020) argues that voluntary incarceration of woman during Covid 19, "holds the imminent danger of 're-housewifization' and falling into the 'domesticity trap' for many [...] The clichéd 'work-life balance' has morphed into 'work-work balance' at home! [...] If a man cooks 'once in a while, it becomes a performative act' (which social media laps up, consumes, reconsumes), whereas when a woman cooks, cleans and the rest, 'she is just doing what is her job".

Pandemic is not something new to PWD's as they have been leading the same lifestyle even before. The disabled people come across various hindrances at multiple levels. The barriers are not just restricted to their physical movement but are engrained in the forms of attitudinal and communication strategies. These limitations disallow them from exercising their basic human rights. The patriarchal setup of the society makes no difference in its treatment of abled and disabled women. These laws stand uncompromised in every situation and cannot be mitigated at any cost. Even though the treatment is same, the experiences of these are not at all same. Each individual woman has her own singularity of experience and cannot be homogenised with rest of the experiences. Thus, these policies which are created taking into consideration the generalised experiences, fails to address the heterogeneity of their existence and experiences. Each individual does not respond and react to a similar situation in a similar manner. The failure to address this differentially speaks a lot about the general attitude of policy makers towards the disabled community. Issues of poverty, unemployment, inadequate social protection measures, institutionalization, and absence of genuine representation of data are some of the issues which need immediate redressal.

The present norm of social behaviour has become a part and parcel of daily life. The disabled can be independent to some extent with the help of technological aids but humans can't lead a life with gadgets and assistance aids alone. Today, everything is made available online. But 
5 | A Pandemic Circumscribing another Pandemic: The Covid 19 World of Disabled Women

since, India is still in the process of digitalization, this facility to reach the remotest corners and be accessible to all is still a dream. A single click can't fetch them a coffee to their table in the house and contactless delivery would not be of any help. Unless a person is using a motorised wheelchair in an accessible house, they could not come to pick the delivery item. In this manner, lockdown has further limited the already-so-little freedom of disabled in the face of new norms of social distancing. Those without sight also have the desire to see and feel things. Nowadays, there remains a constant suspicion that the person helping the other could as well be a corona positive. At the same time, people are afraid to help those in needs solely because the one they want to help could as well be corona affected. Covid 19 is pandemic in pandemic in the life of WWD's, due to their social isolation, not just due to pandemic but also because of stigma associated with disability and gender which results in violence against disabled women.

\section{References}

Express news service, (October 19 2020), NPRD condemns girl's rape, murder; tells police, admn to be sensitive, The Indian Express. Ahmedabad, https://indianexpress.com/article/cities/ahmedabad/gujarat-nprd-condemns-girls-rapemurder-tells-police-admn-to-be-sensitive-6779769/

Natu, Sadhana, (October 2020), Covid \& Crisis of Care: Feminist psychological view, Miloon Saryajani, https://miloonsaryajani.in/crisis-of-care-in-covid-times-view-from-a-feministpsychological-lens-sadhana-natu/

PTI, (Mar 31 2020). Domestic Abuse Cases Rise as Covid 19 Lockdown Turns into Captivity for many Women, The Deccan Herald, New Delhi. https://www.deccanherald.com/national/northand-central/domestic-abuse-cases-rise-as-covid-19-lockdown-turns-into-captivity-formany-women-819653.html

Rising Flames and Sightsavers India (2020), 'Neglected and Forgotten; women with disabilities during the covid crisis in India', Mumbai, Retrieved from https://risingflame.org/wpcontent/uploads/2020/o7/NeglectedAndForgotten_RFandSS.pdf

Tremain. Shelley, (April 2020) COVID-19 and The Naturalization of Vulnerability, Biopolitical Philosophy, https://biopoliticalphilosophy.com/2020/o4/o1/covid-19-and-thenaturalization-of-vulnerability/

WHO, (july, 1997), violence against women definition and scope of the problem, Retrieved from https://www.who.int/gender/violence/v4.pdf

Yashika Budhwar. (May 24 2020). Mentally-Ill-Girl-Raped, Killed by Brother, Friends in Jaipur, Times of India, Jaipur, https://timesofindia.indiatimes.com/city/jaipur/mentally-ill-girlraped-killed-by-brother-friends/articleshow/75928102.cms

\section{Bio note:}

Gokul S is a research Scholar in the Department of English Literature, The English \& Foreign Languages University, Hyderabad. For his doctoral study, he is pursuing research on disability studies in specific to the Indian disabled women life narratives." His areas of interest are disability and gender, representation of disabled and social policy. He can be reached at gokulloyolaı@gmail.com 